ORIGINAL ARTICLE

\title{
A longitudinal observation of early pulmonary responses to cotton dust
}

\author{
X-R Wang, L-D Pan, H-X Zhang, B-X Sun, H-L Dai, D C Christiani
}

Occup Environ Med 2003;60:115-121

See end of article for authors' affiliations

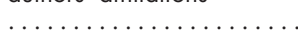

Correspondence to: Dr D C Christiani,

Occupational Health

Program, Harvard School

of Public Health, 665

Huntington Avenue,

Boston, MA 02115, USA

dchris@hohp.harvard.edu

Accepted 20 June 2002

\begin{abstract}
Aims: To examine early adverse pulmonary effects of exposure to cotton dust, and to identify potential risk factors, including atopy for pulmonary responses to cotton dust.

Methods: Spirometry, methacholine challenge testing, and questionnaire; performed among 101 nonsmoking newly hired textile workers at baseline (prior to starting work), and at 3, 12, and 18 months after starting work. Concentrations of airborne cotton dust in various work areas were measured at each follow up survey using vertical elutriators.

Results: The incidence of non-specific respiratory symptoms was $8 \%$ at three months, then diminished afterwards. Substantial acute cross shift drops in FEV, at each follow up survey, and longitudinal declines in FVC and FEV after 12 months of exposure were observed. Airway responsiveness to methacholine increased with follow up time, and was more pronounced among atopics. Increasing airway responsiveness was strongly correlated with cross shift drops in $\mathrm{FEV}_{1}$. In addition, one or more respiratory symptoms at three months was significantly, and pre-existing atopy marginally significantly, associated with cross shift drops in FEV, after adjusting for other covariates and confounders.

Conclusion: Results suggest that non-specific respiratory symptoms, decreasing lung function, and increasing airway responsiveness are early pulmonary responses to cotton dust. In addition, the occurrence of respiratory symptoms and increasing airway responsiveness, as well as atopy, may be important predictors for acute changes in lung function among cotton textile workers.
\end{abstract}

O ccupationally related exposure to cotton dust has been implicated in exacerbation of airway diseases including byssinosis, ${ }^{12}$ chronic bronchitis, ${ }^{34}$ and pulmonary function impairments. ${ }^{56}$ Most of the previous studies have focused on the typical syndrome of byssinosis, which is described as a feeling of chest tightness and shortness of breath that occurs on the first day of the working week, progressing to include other days in advanced stages. It has been known that attacks of typical byssinosis usually begin to appear after several years of exposure, ${ }^{1}$ and earlier pulmonary responses to cotton dust may be characterised by reversible respiratory symptoms and acute decrements in lung function. $^{78}$

Among the few studies that have assessed pulmonary responses to cotton dust in the early stages of exposure, Sepulveda and colleagues ${ }^{9}$ observed a significant decrement in FEV after exposure to $1.02 \mathrm{mg} / \mathrm{m}^{3}$ of elutriated cotton dust in model cardrooms for six hours in 226 healthy and nonasthmatic volunteers. The mean $\mathrm{FEV}_{1}$ decline, however, was found to be significantly greater in atopic subjects, defined by skin prick tests, than in non-atopic subjects. Another experimental study ${ }^{10}$ reported significantly higher bronchial reactivity after exposure to cotton dust for five hours in 57 non-smoking and non-asthmatic volunteers, while atopic subjects (defined by questionnaire) had higher reactivity than non-atopics. These studies suggest that non-specific airway responsiveness and atopic status may be two potential markers related to the variability of the acute response to cotton dust. However, expanded follow up studies on the early pulmonary response to cotton dust have been rare.

To provide additional information in understanding the adverse effects of cotton dust inhalation at the early stage of exposure, a follow up study was undertaken among a group of newly hired cotton textile workers. Because all the workers of the cohort were lifelong non-smokers, this population provided a unique opportunity to observe relatively pure effects of exposure to cotton dust. The aims of the current analysis were to determine the changes in lung function, nonspecific airway responsiveness, and respiratory symptoms caused by exposure to cotton dust, and to ascertain whether there is a difference in pulmonary responses between atopic and non-atopic persons.

\section{SUBJECTS AND METHODS \\ Study subjects}

The study was approved by the Institutional Review Boards of the Harvard School of Public Health and the First Hospital of the Shanghai Textile Industry. The original cohort was recruited from newly hired workers at three state owned cotton mills (mill 1-3) in Shanghai, China. A total of 240 workers who were assigned to the yarn preparation areas participated in the baseline survey conducted in March 1997. Among 15 excluded workers were nine males, five females with respiratory disease prior to work, and another one lacking a completed questionnaire. Therefore, the final cohort consisted of 225 female new workers without cardiorespiratory disease and respiratory symptoms. All workers were nonsmokers with an average age of 18 years (range 16-29 years) at the outset, and not previously exposed to industrial dusts. Their socioeconomic status, geographical area, education level, and occupation were homogeneous.

The follow up surveys were carried out at 3, 12, and 18 months after the workers started to work in the cotton mills. A total of $194(86 \%)$ and 136 workers $(61 \%)$ of the original cohort were followed at 3 months and 12 months, respectively. The production and working conditions were stable over the period. After the 12 month survey, however, all of these workers were merged into one of the three cotton mills, because the

Abbreviations: BTPS, body temperature and pressure saturated with water vapour; $\mathrm{FEV}_{1}$, forced expiratory volume in 1 second; $F V C$, forced vital capacity; GEE, generalised estimating equation 
Table 1 Available environmental measurement data by mill

\begin{tabular}{|c|c|c|c|c|c|c|}
\hline & \multicolumn{2}{|c|}{ Mill 1} & \multicolumn{2}{|c|}{ Mill 2} & \multicolumn{2}{|c|}{ Mill 3} \\
\hline & $\mathrm{n} \dagger$ & Mean (SD) & $\mathrm{n} \dagger$ & Mean (SD) & $\mathrm{n} \dagger$ & Mean (SD) \\
\hline \multicolumn{7}{|l|}{ Cotton dust $\left(\mathrm{mg} / \mathrm{m}^{3}\right)$} \\
\hline 3 months & 42 & $0.42(0.34)$ & 48 & $0.39(0.32)$ & 48 & $0.64(0.52)$ \\
\hline 12 months & 56 & $0.32(0.33)$ & & - & 56 & 1.05 (1.19) \\
\hline 18 months & 56 & $0.47(0.53)$ & & - & & - \\
\hline \multicolumn{7}{|l|}{ Endotoxin $\left(\mu \mathrm{g} / \mathrm{m}^{3}\right)$} \\
\hline 3 months & 42 & $0.22(0.51)^{*}$ & 48 & $1.36(2.07)$ & 48 & $1.07(1.84)$ \\
\hline
\end{tabular}

other two were closed. There were 101 workers who participated in the last survey, representing $45 \%$ of the original cohort. The data of the workers who were followed at either 3 months or 12 months were analysed and reported separately. The current analysis focused on the subset data of 101 workers who were followed throughout the 18 month observation. Of these, 32 workers worked at mill 1, 46 at mill 2, and 23 at mill 3 before the mills were merged.

\section{Environmental assessment}

Environmental airborne cotton dust and Gram negative bacteria endotoxin in various work areas were measured at the 3 month survey. Cotton dust data for mill 1 were available at 12 and 18 months, and for mill 3 at 12 months. The methods used have been described previously. ${ }^{11}$ Vertical elutriators (General Metal Works, Inc., Cleveland, Ohio, USA) were used to take environmental samples using $37 \mathrm{~mm}$ PVC filters, over a full shift (minimum six hours). Endotoxin assays were performed on the dust samples using the Limulus amoebocyte lysate assay, chromogenic method. ${ }^{12}$ There were $8-16$ full shift filters taken from each work area including carding, drawing, cleaning, roving, spinning, twisting, and bobbing. The total samples were 138 for 3 months, 112 for 12 months, and 56 for 18 months from the remaining mill (mill l).

\section{Questionnaires}

Questionnaires collecting information on complete work history, respiratory symptoms, and smoking history were administered at each survey. A modified American Thoracic Society (ATS/DLD) questionnaire ${ }^{213}$ was used. The questionnaire was translated into Chinese and back translated into English to verify accuracy. ${ }^{214}$ The symptoms of interest in the analysis included: usual cough with phlegm, usual dry cough, chest tightness, and dyspnoea. "Usual" was defined as a symptom occurring for more than five days a week. Work related nasal irritation, throat irritation, fatigue, and skin reactions were also observed.

\section{Skin test}

At baseline, each worker was given skin prick testing using standard methods. ${ }^{15}$ Briefly, the volar surface skin was cleaned with alcohol and allowed to dry. Twelve pricks were made in the skin approximately $2 \mathrm{~cm}$ apart with the Greer Scarifier (Greer Labs, Winston-Salem, NC). Subjects were tested with six common local antigens and six standard antigens, including ragweed, mould, standardised mite DF dermatophagoides farinae, mulberry silk, summer pollen, and house dust, along with a glycerine (negative) control. Erythema and induration were measured at 20 minutes by reading two perpendicular lines across the test site. Positive reactions were defined as induration at least $5 \times 5 \mathrm{~mm}$ after subtracting diameters of negative control reactions. We reported the results of response to local antigens only, since the results of response to local antigens and to standard ones were almost identical. Atopy was defined as a positive reaction to two or more allergen extracts.

\section{Lung function testing}

Spirometric measurements were conducted by a trained technician using an 8 litre water sealed field spirometer (W.E. Collins Co., Braintree, MA) calibrated twice each day with a 3 litre syringe. At follow up surveys, forced expiratory spirograms were performed before and after work shifts (cross shift) on the first day back to work after a two day rest. Each worker performed up to seven trials to produce three acceptable curves. The analysis of the study focused on indices of expiratory volume in one second $\left(\mathrm{FEV}_{1}\right)$ and forced vital capacity (FVC). Acceptable $\mathrm{FEV}_{1}$ tracings were allowed to vary by no more than $5 \%$ or $100 \mathrm{ml}$, whichever was greater, and the best $\mathrm{FEV}_{1}$ and FVC were used regardless of whether they were on the same tracing. All values were corrected to conditions of body temperature and pressure saturated with water vapor (BTPS). The same technicians, instruments, and standardised methodology were used throughout the study.

\section{Non-specific airway responsiveness}

A test of non-specific airway responsiveness was performed at baseline, and at the 12 month and 18 month follow up surveys, respectively, using graded doses of inhaled methacholine. ${ }^{16}$ The methacholine challenge was done before work shift in the first day after a two day break at the 12 and 18 month surveys. Solutions were inhaled through a nebuliser (airflow $8 \mathrm{l} / \mathrm{min}$, output $0.3 \mathrm{ml} / \mathrm{min}$ ). The subjects inhaled the aerosol in a sitting position, at quiet breathing for two minutes through the nebuliser. They first inhaled phenol buffered saline alone to provide a control baseline spirometric value, then inhaled methacholine solution according to the following concentration schedule: $0.5,1,2,5,10$, and $25 \mathrm{mg} / \mathrm{ml}$. Spirometry was measured 60-120 seconds after each dose level inhalation. The test was terminated when a $15 \%$ decline in $\mathrm{FEV}_{1}$ from the post-diluent value occurred or when the methacholine concentration of $25 \mathrm{mg} / \mathrm{ml}$ was reached. Results were expressed as the decrease of $\mathrm{FEV}_{1}$ at the highest dose of methacholine given minus post-diluent value.

\section{Total serum IgE measurement}

Total serum IgE concentration using a modified classical radioimmunosorbent tes $\mathrm{t}^{17}$ was examined at baseline, and each follow up survey.

\section{Statistical analysis}

Data analysis focused on the changes in lung function and non-specific airway responsiveness over the 18 months after the workers started to work in the cotton mills. The possible impact of atopy on these changes was examined. The lung function data were expressed as longitudinal changes in $\mathrm{FEV}_{1}$ and FVC (using pre-shift values), and as acute changes (using cross shift drops in $\left.\mathrm{FEV}_{1}\left(\Delta \mathrm{FEV}_{1}\right)\right)$ over the follow up period. Changes in airway responsiveness were assessed as differences in decrease of $\mathrm{FEV}_{1}$ at the highest dose of methacholine (25 $\mathrm{mg} / \mathrm{ml}$ ) between follow up surveys and baseline survey. Personal exposure of individual workers during each follow up 
Table 2 Characteristics of followed and dropout workers at 18 months

\begin{tabular}{|c|c|c|}
\hline & $\begin{array}{l}\text { Followed } \\
(n=101)\end{array}$ & $\begin{array}{l}\text { Dropouts } \\
(n=124)\end{array}$ \\
\hline Age at baseline, $y$ & 18.5 (1.7) & $18.3(1.6)$ \\
\hline Height at baseline, $\mathrm{cm}$ & $160.5(4.3)$ & $160.4(4.4)$ \\
\hline Atopy at baseline, $\mathrm{n}(\%)$ & $31 \quad(30.7)$ & $37 \quad(29.8)$ \\
\hline \multicolumn{3}{|l|}{ Symptoms $\dagger, \mathrm{n}(\%)$} \\
\hline 3 months & 8 (7.9) & 12 (9.7) \\
\hline 12 months & $2(2.0)$ & (4.0) \\
\hline \multicolumn{3}{|l|}{ FVC, $\mathrm{ml}$} \\
\hline Baseline & $3103.6(428.1)$ & $3086.6(398.1)$ \\
\hline 3 months & 3111.1 (388.2) & $3106.4(386.7)$ \\
\hline 12 months & 2941.7 (403.7) & 3051.5 (372.6) \\
\hline \multicolumn{3}{|l|}{$\mathrm{FEV}_{1}, \mathrm{ml}$} \\
\hline Baseline & $2722.0(383.2)$ & $2762.3(350.1)$ \\
\hline 3 months & $2765.6(346.2)$ & 2805.5 (331.0) \\
\hline 12 months & 2638.6 (339.0) & $2718.0(340.5)$ \\
\hline \multicolumn{3}{|l|}{$\Delta \mathrm{FEV}_{1} \ddagger, \mathrm{ml}$} \\
\hline 3 months & $-31.1(82.7)$ & $-26.8(79.4)$ \\
\hline 12 months & $-27.7(62.3)^{*}$ & $-48.6(63.6)$ \\
\hline
\end{tabular}

Results expressed as mean (SD) unless stated otherwise.

$\dagger$ Either dry cough or cough with phlegm; łcross shift change in $\mathrm{FEV}_{1}$. ${ }^{*} \mathrm{p}<0.05$ in comparison with the dropouts.

period was assigned to high or low level according to the median values of dust (or endotoxin) concentrations of their work area measured at each time.

A paired $t$ test was used to compare the differences between baseline and follow up data, and Student's $t$ test, Wilcoxon rank sum test, or Fisher's exact test to compare the differences between atopic and non-atopic workers. Pearson correlation analysis including all the available data over the 18 months was applied to determine correlation between airway responsiveness and acute or longitudinal spirometric changes. Finally, generalised estimating equation (GEE) analysis was accomplished to determine predictive variables for changes in lung function and airway responsiveness with identity link function and independence correlation structure. Candidate variables included atopic status, exposure level, respiratory symptoms, and serum IgE concentrations. In addition, age, height, and mill at 3 and 12 months were also considered as covariates. The GEE models were fitted using all available spirometric and airway responsiveness measurements taken from all surveys (time varying dependent variables). Cotton dust exposure level and IgE concentrations were time varying independent variables. Time fixed independent variables included age, height, and atopic status at baseline, respiratory symptoms and exposure to endotoxin at 3 months. Serum IgE concentrations were logarithmically transformed $(\log 10)$ for the analysis because of highly skewed distribution. Data analysis was carried out with SAS personal computer software (version 8, SAS Institute, Cary, NC, 1999).

\section{RESULTS}

Table 1 shows the environmental measurement data throughout the follow up period. According to the available data, dust concentrations were highest in mill 3, whereas dust level in mill 1 was stable during the 18 months. There was a large difference in endotoxin among the three mills, of which a significantly lower level was in mill 1 . Irrespective of mill or survey, the dust concentrations were highest in carding, followed by drawing, and lowest in the spinning area. The trend was similar for endotoxin. Spearman correlation coefficient between dust and endotoxin measured at 3 months was moderately high $(r=0.73 ; \mathrm{p}<0.0001)$. The majority of the workers remained in a same work area until the 12 month follow up survey. After the mills were merged by the 18 month survey, more workers joined in carding and drawing areas where the concentration of cotton dust was relatively higher. The total median concentrations of cotton dust (all three mills) were $0.35 \mathrm{mg} / \mathrm{m}^{3}$ at 3 months, $0.27 \mathrm{mg} / \mathrm{m}^{3}$ (mills 1 and 3 ) at 12 months, and $0.28 \mathrm{mg} / \mathrm{m}^{3}$ (mill l) at 18 months. The median concentration of endotoxin at 3 months was 0.037 $\mu \mathrm{g} / \mathrm{m}^{3}$.

To examine a potentially differential loss to follow up that may be a source of selection bias, demographic features, and health status for the analysed subset of 101 workers and the dropouts at 18 months were compared using Student's $t$ test for continuous variables and Fisher's exact test for category

Table 3 Changes in spirometric parameters, airway responsiveness, and $\lg E$ over 18 month observation

\begin{tabular}{|c|c|c|c|}
\hline & All workers $(n=101)$ & Atopics $(n=31)$ & Non-atopics $(n=70)$ \\
\hline \multicolumn{4}{|l|}{$\mathrm{FVC} \dagger, \mathrm{ml}$} \\
\hline 3 months & 17.6 (19.1) & $67.5(31.5)^{*}$ & $-5.7 \quad(23.5)$ \\
\hline 12 months & $-157.3(19.5)^{* *}$ & $-158.9(34.8)^{* *}$ & $-156.6(23.7)^{* *}$ \\
\hline 18 months & $-165.6(24.7)^{* *}$ & $-144.3(48.1)^{* *}$ & $-175.4(28.6)$ ** \\
\hline \multicolumn{4}{|l|}{$\mathrm{FEV}_{1} \dagger, \mathrm{ml}$} \\
\hline 3 months & $49.1(17.8)^{* *}$ & $78.4(17.6)^{* *}$ & $35.5 \quad(24.6)$ \\
\hline 12 months & $-77.5(16.1)^{* *}$ & $-66.4(16.4)^{* *}$ & $-82.0(21.7)^{* *}$ \\
\hline 18 months & $-40.8(19.5)^{*}$ & $-12.2 \quad(23.6)$ & $-52.6(25.7)^{*}$ \\
\hline \multicolumn{4}{|l|}{$\Delta \mathrm{FEV}_{1} \ddagger, \mathrm{ml}$} \\
\hline 3 months & $-31.1 \quad$ (9.3) & $-38.1 \quad(15.4)$ & -27.7 (11.7) \\
\hline 12 months & -27.7 (7.0) & $-33.3(15.5)$ & $-25.3(7.5)$ \\
\hline 18 months & $-24.7 \quad(8.4)$ & $-39.5 \quad(17.5)$ & $-18.2 \quad(9.3)$ \\
\hline \multicolumn{4}{|c|}{$\% \Delta \mathrm{FEF}_{1} \geqslant 5 \%(\mathrm{n})$} \\
\hline 3 months & $15.8 \quad(16)$ & 6.5 (2) & $20.0 \quad(14)$ \\
\hline 12 months & 8.9 (9) & $16.1 \quad(5)$ & 5.7 (4) \\
\hline 18 months & $17.8 \quad(18)$ & 25.8 (8) & 14.3 (10) \\
\hline \multicolumn{4}{|c|}{ Change in $\mathrm{FEV}_{1}$ at highest methacholinet, $\mathrm{ml}$} \\
\hline 12 months & $-26.2(19.3)$ & $-47.2(36.4)$ & $-16.3(22.7)$ \\
\hline 18 months & $-16.3(18.8)$ & $-63.5(24.2)^{*}$ & $3.8(23.6)$ \\
\hline \multicolumn{4}{|c|}{$\log [\lg E] \dagger, \log \mathrm{mg} / \mathrm{dl}$} \\
\hline 3 months & $0.25(0.05)^{* *}$ & $0.35(0.08)^{* *}$ & $0.20(0.06)^{* *}$ \\
\hline 12 months & $-0.04(0.06)$ & $0.01(0.07)$ & $-0.06(0.08)$ \\
\hline 18 months & $-0.08(0.07)$ & $-0.04(0.12)$ & $-0.10(0.08)$ \\
\hline
\end{tabular}

Results expressed as mean (SE) unless stated otherwise.

tRelative to baseline data; ${ }^{*} \mathrm{p}<0.05,{ }^{*}{ }^{*} \mathrm{p}<0.01$ in comparison with baseline data (paired $t$ test).

$\ddagger$ Cross shift change in FEV

None of the variables was statistically significant in comparison with atopics and non-atopics. 
variables. Wilcoxon rank sum test was also applied to compare cross shift changes in FEV , because of a skewed distribution of the variable with the large standard deviation. As table 2 shows, the demographic data were comparable, but the dropout subset had a slightly higher proportion of respiratory symptoms at either 3 or 12 months and a significantly greater cross shift change in $\mathrm{FEV}_{1}$ at 12 months. The proportion of atopy in followed up workers $(31 \%)$ was close to that in dropouts $(30 \%)$. The data suggested that dropouts at 18 months had a poorer respiratory condition than the 101 workers followed throughout the 18 months.

Of 101 workers, $31(31 \%)$ were designated as atopic subjects, and the remaining 70 as non-atopic ones according to their results of skin prick test at baseline. As a whole group, the average age was 18.5 years and height $160.5 \mathrm{~cm}$ at baseline. There were no differences in age, height, baseline $\mathrm{FVC}$, or $\mathrm{FEV}_{1}$ for atopic and non-atopic workers, while the drop in $\mathrm{FEV}_{1}$ at the highest methacholine dose at baseline was slightly greater in the non-atopics $(87 \mathrm{ml})$ than in the atopics $(58 \mathrm{ml})$. Forty seven per cent of workers of the whole group were assigned into being exposed to higher dust level at 18 months, while only $16 \%$ were so classified at 3 months and $22 \%$ at 12 months. The proportions of exposure to higher dust level were significantly higher in the non-atopic subgroup at $12(\mathrm{p}=0.04)$ and 18 months $(\mathrm{p}=0.02)$.

Table 3 shows the acute and longitudinal changes in spirometry, changes in $\mathrm{FEV}_{1}$ at the highest methacholine concentration, and $\log [\operatorname{IgE}]$ after initiating work in cotton mills. As a whole group, no decrements in FVC and $\mathrm{FEV}_{1}$ were found at 3 months, in comparison with baseline values. At 12 months, however, statistically significant declines in both parameters were observed. On the other hand, substantial cross shift drops in FEV, were noted at the 3 month survey, and similar drops remained at the following surveys. Even at 3 months, $16 \%$ of workers were found to have an acute drop of $5 \%$ or more. Atopic and non-atopic workers showed similar declines in longitudinal changes in FVC and $\mathrm{FEV}_{1}$ since 12 months, but the atopics appeared to have a greater cross shift drop in FEV at each follow up survey. Moreover, the proportion of acute drop by $5 \%$ or more tended to increase with the time in the atopics, whereas no such a trend was seen in the non-atopics.

Overall, $\mathrm{FEV}_{1}$ at the highest methacholine dose dropped by $26 \mathrm{ml}$ at 12 months, and by $16 \mathrm{ml}$ at 18 months, when compared with the baseline values. Atopics had greater drops at 12 and 18 months than did the non-atopics, and the value at 18 months was statistically significantly different from that at baseline $(p<0.05)$. Log [ IgE] was significantly increased at 3 months and almost returned to the baseline level at 12 and 18 months for all the workers. Both atopic and non-atopic workers had significantly increased $\log [\operatorname{IgE}]$ at 3 months, while the atopics had an insignificantly higher $\log [\operatorname{IgE}]$ than did the nonatopics at 3 months.

Eight of 101 workers $(8 \%)$ reported either cough with phlegm or dry cough at 3 months; an additional three had nasal irritation, and two throat irritation, in spite of the fact that none of the workers had respiratory disease or symptoms at baseline. The frequency of the respiratory symptoms reported at the following two surveys was $2 \%$ and $1 \%$, respectively, which was less than at 3 months. Atopic workers did not report more symptoms than non-atopic workers. No byssinosis was observed among these workers during the observation time.

Dose-response characteristics of methacholine challenge testing done at baseline, 12 months, and 18 months were compared. As a whole group, airway responses to methacholine increased with time- that is, the lowest at baseline and the highest at 18 months. The average drop in FEV at the highest methacholine dose $(25 \mathrm{mg} / \mathrm{ml})$ was $97 \mathrm{ml}$ at 18 months. A trend for the change with time was seen more distinctly in the atopics than in the non-atopics (fig 1). In the former, the $\mathrm{FEV}_{1}$ drops in response to each dose were greater
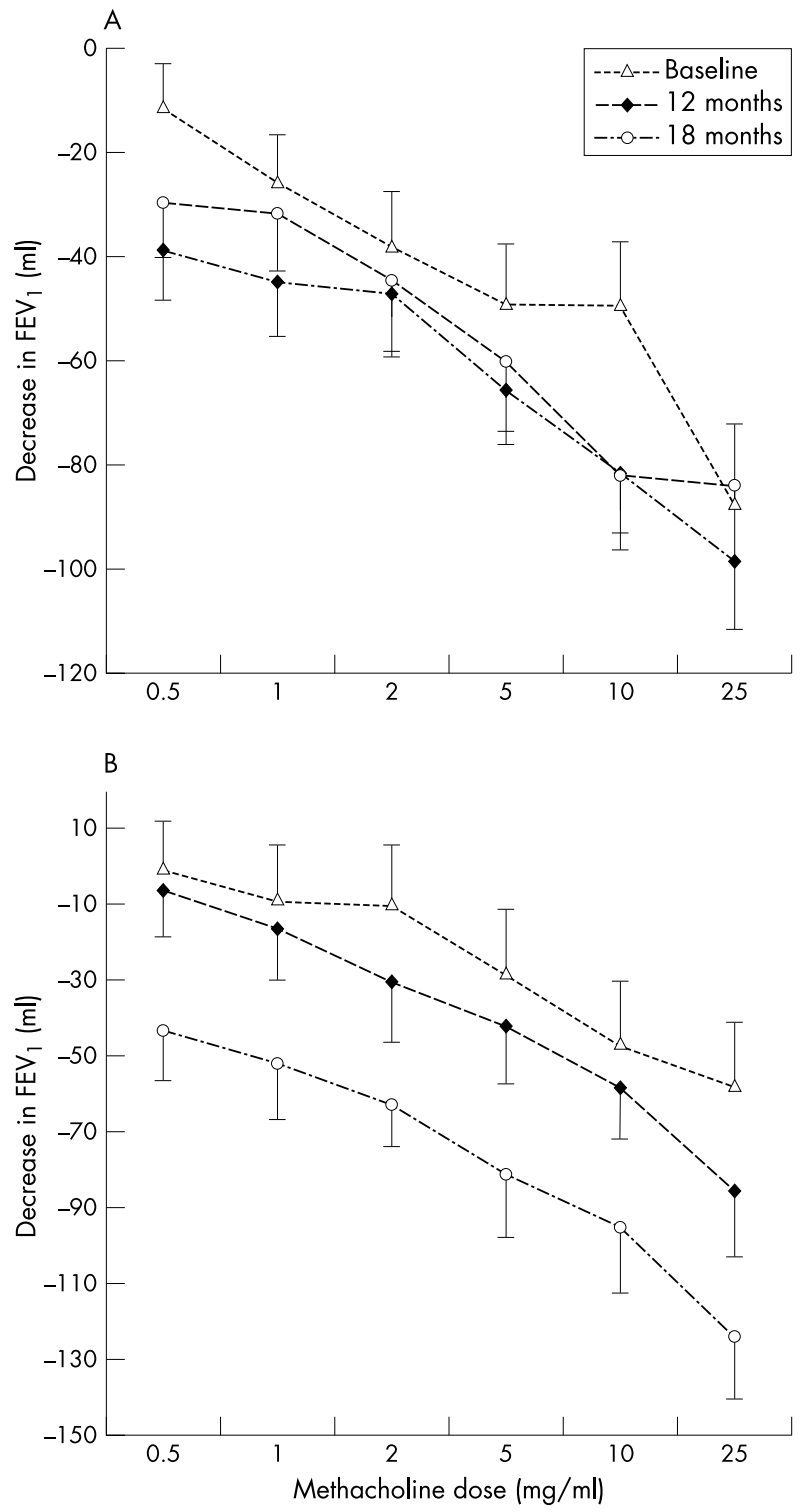

Figure 1 Methacholine dose-response characteristics of $(A)$ non-atopic $(n=70)$ and $(B)$ atopic workers $(n=31)$ over 18 months follow up observation. Data are given as mean and SEM.

at 18 months than at baseline and 12 months, reaching $124 \mathrm{ml}$ of the average drop at the highest dose. This trend, however, was not evident in the non-atopics, whose airway responsiveness at 18 months was less than at 12 months.

Pearson correlation analysis including all the workers showed that changes in airway responsiveness were significantly correlated with the cross shift changes in $\mathrm{FEV}_{1}$ $(r=0.25, \mathrm{p}<0.0001)$, but not significantly with the longitudinal changes in either FVC or $\mathrm{FEV}_{1}(r=0.09, \mathrm{p}>0.05$ for both).

In GEE analysis, longitudinal changes in FVC, $\mathrm{FEV}_{1}$, or airway responsiveness were not predicted by atopy, symptoms, exposure level, or IgE level (data not shown). However, for cross shift drops in $\mathrm{FEV}_{1}$ over the follow up period, respiratory symptoms reported at 3 months were found to be a significant predictor and atopy to be a marginally significant predictor (table 4). In addition, exposure to high dust levels was negatively associated with greater acute drops in $\mathrm{FEV}_{1}$, though not statistically significant. When the term of exposure to high endotoxin at 3 months was added, as shown in model 2, exposure to high dust contributed more to cross shift drops in $\mathrm{FEV}_{1}$ 
Table 4 GEE analysis for cross shift changes in FEV, over 18 month observation

\begin{tabular}{|c|c|c|c|c|}
\hline & \multicolumn{2}{|l|}{ Model 1} & \multicolumn{2}{|l|}{ Model 2} \\
\hline & Estimate (SE) & $p$ value & Estimate (SE) & $\mathrm{p}$ value \\
\hline Intercept & 13.37 (15.09) & 0.37 & 13.21 (15.09) & 0.38 \\
\hline Atopy & $-23.39(13.06)$ & 0.07 & $-23.29(12.93)$ & 0.07 \\
\hline Symptoms* & $-36.91(16.47)$ & 0.02 & $-37.02(16.47)$ & 0.02 \\
\hline Exposure to high dust & $-19.89(16.43)$ & 0.23 & $-27.77(19.30)$ & 0.15 \\
\hline $\log [\lg E], \log \mathrm{mg} / \mathrm{dl}$ & $3.84(9.66)$ & 0.69 & $3.46(9.59)$ & 0.71 \\
\hline Mill $2 v$ mill $1 \dagger$ & $-53.95(14.84)$ & 0.000 & $-56.56(15.58)$ & 0.000 \\
\hline Mill $3 v$ mill 1 & $-33.98(17.02)$ & 0.05 & $-33.82(17.01)$ & 0.05 \\
\hline Exposure to high endotoxin $\ddagger$ & & & $8.88(11.26)$ & 0.45 \\
\hline
\end{tabular}

$(-28 \mathrm{ml})$ in comparison with that $(-20 \mathrm{ml})$ in model $\mathrm{l}$ without the term of exposure to high endotoxin. This might reflect an interactive effect of exposure to cotton dust and to endotoxin, as their measurements were significantly correlated. When exposure to dust was removed from model 2, exposure to high endotoxin at 3 months turned to be negatively related to cross shift $\mathrm{FEV}_{1}(-8 \mathrm{ml})$, suggestive of an adverse effect of endotoxin on the outcome variable.

Working at mills 2 and 3 was found to be significantly associated with a greater drop in $\mathrm{FEV}_{1}$ than working at mill 1 , which was consistent with the result that mill 1 was lowest in concentrations of both dust and endotoxin. Age and height at baseline were also considered in all of the models. They were significantly related to longitudinal changes in FEV and FVC, but not to the cross shift drops in $\mathrm{FEV}_{1}$. These two variables were removed from the final models to improve the model fitting. When airway responsiveness to methacholine (drops in $\mathrm{FEV}_{1}$ at highest does) over the 18 months was added to either model 1 or 2, it was strongly associated with the cross shift drops in $\mathrm{FEV}_{1}(\mathrm{p}<0.001)$, while atopy and respiratory symptoms were not. This finding suggests a stronger relation between cross shift changes in $\mathrm{FEV}_{1}$ and increasing airway responsiveness in these workers.

\section{DISCUSSION}

This study observed pulmonary responses to cotton dust during the first 18 months of exposure. The cohort was made up of same gender, lifelong non-smoking and previous nonexposed newly hired workers, with no pre-existing cardiorespiratory diseases and/or chest symptoms. Our results need to be interpreted in light of some limitations. There was a great attrition of the original cohort, especially after one year, largely because of a merger of the cotton mills (from three mills to one), leading to a number of workers leaving from the industry. The dropout workers at 18 months were found to have more respiratory symptoms at either 3 or 12 months, and a significantly greater drop in cross shift $\mathrm{FEV}_{1}$ at 12 months in comparison with the followed workers. It suggests that the dropouts were likely to be more predisposed to the effects of cotton dust. Hence, this study could be subject to a "healthy worker effect", leading the health outcomes related to cotton dust exposure being underestimated. In spite of that, the findings of this study are informative and helpful in further understanding the natural history of pulmonary responses to exposure to cotton dust at the earliest stage of exposure.

We showed a remarkable change in lung function, not only reflected in acute drops, but also in longitudinal declines. A substantial cross shift drop in $\mathrm{FEV}_{1}$ was seen at each follow up point since the workers started to work in the cotton mills. This acute drop was most likely explained by the effects of exposure to cotton dust, as observed in healthy volunteers. ${ }^{78}$ Similar results were reported recently by another one year follow up study in a group of newly hired textile workers. ${ }^{18}$ How- ever, unlike our study, that study included both smokers and non-smokers, and did not exclude persons who had respiratory symptoms or/and disease prior to work in cotton mill. We found that atopic workers had a greater acute drop in FEV over the follow up time than non-atopic workers; the difference was marginally significant after other covariates and confounders were considered in the GEE models. The greater acute drop observed in the atopics could not be explained by their exposure to higher levels of dust. As a matter of fact, fewer people in the atopics were exposed to higher dust levels than in the non-atopics. Atopy may be an important risk factor for the cotton dust related acute lung function change. Moreover, we observed a significant contributing effect of respiratory symptoms reported at three months to the acute spirometric changes.

In addition to the acute drops, longitudinal changes in lung function were detectable in these workers. FVC and $\mathrm{FEV}_{1}$ at 12 and 18 months were significantly lower than the baseline values. We noted that the average decline in $\mathrm{FEV}_{1}$ at the first one year $(-78 \mathrm{ml})$ in these newly hired workers was greater than the annual decline observed at five years or 15 years on female textile workers who were exposed to cotton dust for a longer time. ${ }^{11}{ }^{19}$ However, the decline in $\mathrm{FEV}_{1}(-41 \mathrm{ml})$ at 18 months tended to be smaller than at one year, while FVC remained similar at 12 and 18 months. Although the change in $\mathrm{FEV}_{1}$ indicated a reversible trend, the question as to whether these changes really represent an early reversible pulmonary response cannot be answered unless a longer observation is undertaken.

Unlike the acute drops in $\mathrm{FEV}_{1}$, there was no significant relation of longitudinal spirometric changes to atopy. Few studies have been available addressing whether atopy is a risk factor for longitudinal change in lung function. One study using cotton dust surveillance data found no significant relation between self reported history of atopy and annual changes in $\mathrm{FEV}_{1}$ or $\mathrm{FVC}^{20}$ Likewise, Li et al, in their one year follow up study ${ }^{18}$ did not observe a significant difference between the atopics and non-atopics that were defined by skin response to cotton dust extract. However, it may be too premature to draw a conclusion on this issue based on the existing limited data and short time observation.

There was a difference in non-specific airway responsiveness between pre-exposure and post-exposure in these workers. Airway responsiveness to methacholine was increased after exposure for either 12 or 18 months, and atopics tended to develop more airway responsiveness than the non-atopics. Several experimental studies reported pre-exposure airway responsiveness related to changes in lung function or increasing airway responsiveness related to exposure to cotton dust. ${ }^{21}$ Nevertheless, few epidemiological studies could assess a longitudinal change in airway responsiveness in cotton textile workers. In this study, we found that increasing methacholine responsiveness was strongly associated with the 
cross shift drops in $\mathrm{FEV}_{1}$ in response to cotton dust. This finding is in agreement with that observed in volunteers in the model cardroom ${ }^{10}$ and suggests that airway hyperresponsiveness is both a risk factor for, and a respiratory effect of exposure to cotton dust. Non-specific airway responsiveness is also associated with airway inflammation, ${ }^{23}$ which may explain its relation to the cross shift drop in $\mathrm{FEV}_{1}$ induced by cotton dust exposure.

The importance of increased non-specific airway responsiveness in the development of chronic airflow limitation in cotton textile workers remains unclear. In this study, there was no direct evidence linking non-specific airway responsiveness with longitudinal changes in lung function. Atopy appeared to interact with exposure to cotton dust, reflecting in both increasing non-specific airway responsiveness and increasing acute drops in lung function. In consideration of a reported positive relation between acute drops and chronic declines in lung function, ${ }^{11}{ }^{19}$ there is a reason to assume that atopic workers may be at a greater risk for chronic airway limitation at these exposure levels.

Non-specific respiratory symptoms appeared to be the earliest pulmonary response to cotton dust. There was no difference in the incidence (at 3 months) or prevalence (at 12 or 18 months) of symptoms between the atopics and non-atopics, suggesting that both atopic and non-atopic workers experienced an inflammatory airway response to cotton dust. In contrast to the changes in lung function and airway responsiveness, the reported symptoms did not increase with longer exposure time. There were fewer subjective symptoms reported after one year than at three months. This phenomenon may partly be explained by the reversibility of the symptoms. The symptoms occur as a rapid response to the onset of exposure, and then tolerance develops with continued exposure, as observed in the early stage of byssinosis, and in organic dust toxic syndrome. In addition, the finding of fewer symptoms with time might be affected, more or less, by subject selection of this study, as the dropouts had slightly more symptoms than followed workers at either 3 or 12 months. No matter which circumstance, however, it is interesting to find that the early occurring symptoms may be an important risk factor for subsequent decrement of lung function.

Average IgE was found to be increased at three months, with a higher level in the atopics, and it returned to the pre-exposure level after 12 and 18 months, irrespective of atopic status. The IgE level was not related to lung function changes, suggesting that IgE level might not be the basis for the airway obstruction observed in cotton workers. ${ }^{24}$

A clear exposure-response relation was not observed for either acute or longitudinal pulmonary responses, though exposure to high dust was negatively related to lung function. Several possible explanations were considered. Firstly, the lack of exposure-response relation may be a result of exposure misclassification. Although considerable effort was made to measure dust concentrations of the working place at each follow up survey, no detailed personal exposure information or personal samples were available. Secondly, the limited sample size and great cohort attrition in this study might lead to lack of power to observe a clear exposure-response relation. Thirdly, current knowledge suggests that bacterial endotoxin, rather than cotton dust itself, may be a major causative agent in vegetable dust induced lung disease, as shown in cotton workers and agricultural workers, ${ }^{25-27}$ as well as in animal experimental studies. ${ }^{28}{ }^{29}$ It was impossible to assess the causative importance of endotoxin with the current limited data. We found a strong mill effect on the changes in lung function, and mills 2 and 3 had a significantly higher endotoxin level than mill 1 at 3 months, while their dust levels were similar. Correspondingly, a significantly greater drop in lung function was seen in working at mill 2 or 3 than at mill 1. This finding indicates an exposure-response relation with endotoxin.
In summary, our findings show that exposure to cotton dust was associated with acute and longitudinal changes in lung function and increasing airway responsiveness among healthy newly hired non-smoking workers. Atopy and respiratory symptoms occurring at the earliest time of exposure may be important risk factors for an acute drop in lung function induced by cotton dust. The results also suggest that non-specific airway responsiveness is both a risk factor for acute drops in lung function and a response to cotton dust.

\section{ACKNOWLEDGEMENTS}

The authors thank the members of the Shanghai field team; Professors Gu Xue-qi, Lu Pei-lian, and Ye Ting-ting from Shanghai Medical University; the Shanghai Textile Bureau; workers and staff of the First and Second Textile Mills and the First Silk Mill; Professors Ellen Eisen and David Wegman of the University of Massachusetts at Lowell; Ms Marcia Chertok, Ms Janna Frelich, and Ms Lucille Pothier for research assistance and computer programming; Dr Stephen Olenchock of NIOSH; and Mr Michael Whitmer for endotoxin analysis.

\section{Authors' affiliations}

X-R Wang, D C Christiani, Department of Environmental Health

(Occupational Health Program), Harvard School of Public Health, Boston, Massachusetts, USA

L-D Pan, H-X Zhang, B-X Sun, H-L Dai, First Hospital of the Shanghai Textile Bureau, Shanghai, China

Support by NIOSH Grant RO1OH02421 and NIH Grant ESO0002

\section{REFERENCES}

1 Schilling RSF, Vigiliani EC, Lammers B, et al. A report on a conference on byssinosis. Proceedings of the 14th International Congress on Occupational Health, Madrid, Spain, 1963:137-45.

2 Christiani DC, Eisen EA, Wegman DH, et al. Respiratory disease in cotton textile workers in the People's Republic of China. I. Respiratory symptoms. Scand J Work Environ Health 1986;12:40-5.

3 Berry G, Molyneux MKB, Tombleson JBL. Relationships between dust level and byssinosis and bronchitis in Lancashire cotton mills. Br J Ind Med 1974;31:18-27.

4 Niven RM, Fletcher AM, Picjering CAC, et al. Chronic bronchitis in textile workers. Thorax 1997;52:22-7.

5 Beck GK, Schachter EN, Maunder LR, et al. A prospective study of chronic lung disease in cotton textile workers. Ann Intern Med 1982:97:645-51.

6 Zuskin E, Valic F. Change in the respiratory response to coarse cotton dust over a ten-year period. Am Rev Respir Dis 1995;1 12:417-21.

7 Haglind P, Rylander R. Exposure to cotton dust in an experimental cardroom. Br J Ind Med 1984:41:340-5

8 Rylander R, Haglind P, Lundholm M. Endotoxin in cotton dust and respiratory function decrement among cotton workers in an experimental cardroom. Am Rev Respir Dis 1985;131:209-13.

9 Sepulveda MJ, Castellan RM, Hankinson JL, et al. Acute lung function response to cotton dust in atopic and non-atopic individuals. $\mathrm{Br} J$ Ind Med 1984:41:487-91.

10 Jacobs RR, Boehlecke B, Hage-Hamsten MV, et al. Bronchial reactivity, atopy and airway response to cotton dust. Am Rev Respir Dis 1993; 148:19-24.

11 Christiani DC, Ye TT, Wegman DH, et al. Cotton dust exposure, across-shift drop in $\mathrm{FEV}_{1}$, and five-year change in lung function. Am J Respir Crit Care Med 1994;150:1250-5.

12 Olenchock SA, Christiani DC, Mull JC, et al. Airborne endotoxin concentrations in various work areas within two cotton mills in the People's Republic of China. Biomed Environ Sci 1990:3:443-51.

13 Ferris BG, Epidemiology standardization project. Am Rev Respir Dis 1978; 118 (suppl):55-88

14 Christiani DC, Ye TT, Wegman DH, et al. Pulmonary function among cotton textile workers. A study of variability in symptom reporting, across-shift drop in $\mathrm{FEV}_{1}$, and longitudinal change. Chest 1994; 105:1713-21.

15 Pepys J. Skin testing. Br J Hosp Med 1975;14:412-17.

16 Hendrick DJ, Fabbri LM, Hughes JM. Modification of the methacholine inhalation test and its epidemiologic use in polyurethane workers. Am Rev Respir Dis 1986; 133:600-4.

17 Voller A, Bidwell D. Enzyme-linked immunosorbent assays. In: Rose NR, Friedman H, Fahey IL, eds. Manual of classical laboratory immunology. Washington, DC: American Society for Microbiology, 1978:99-109.

18 Li D, Zhong YN, Rylander R, et al. Longitudinal study of the health of cotton workers. Occup Environ Med 1995;52:328-31.

19 Christiani DC, Wang XR, Pan LD, et al. Longitudinal changes in pulmonary function and respiratory symptoms in cotton textile workers. A fifteen-year follow-up study. Am J Respir Crit Care 200 1; 163:847-53

20 Jennison $\mathbf{E}$, Jacobs RR. Evaluation of the association of acute over shift change in pulmonary function and atopy using OSHA cotton dust surveillance data. Am J Ind Med 1994;25:737-47. 
21 Boehlecke B. Report to NIOSH on Cooperative Agreement. \#81-OH-158, 1982.

22 Schachter EN, Zuskin E, Buck $M$, et al. Airway reactivity and cotton bract-induced bronchial obstruction. Chest 1985;87:51-5.

23 Boushey HA, Holtzman M, Sheller JF, et al. Bronchial hyperreactivity. Am J Respir Dis 1980;121:389.

24 Zuskin E, Kancelijak B, Schachter EN, et al. Immunological findings and respiratory function in cotton textile workers. Int Arch Occup Environ Health 1992;64:31-7.

25 Kennedy SM, Christiani DC, Eisen EA, et al. Cotton dust and endotoxin exposure-response relationships in cotton textile workers. Am Rev Respir Dis 1987; 135: 194-200.
26 Castellan RM, Olenchock SA, Kinsley KB, et al. Inhaled endotoxin and decreased spirometric values. An exposure-response relation for cotton dust. N Engl J Med 1987;317:605-10.

27 Schwartz DA, Donham KJ, Olenchock SA, et al. Determinants of longitudinal changes in spirometric function among swine confinement operators and farmers. Am J Respir Crit Care Med 1995;151:47-53.

28 Snella MC, Rylander R. Endotoxin inhalation induces neutrophil demotaxis by alveolar macrophages. Agents Actions 1985;16:521-6.

29 Lantz RC, Birch K, Hinton DE, et al. Morphometric changes of the lung induced by inhaled bacterial endotoxin. Exp Mol Pathol 1985;43:305-20.

\section{OEM web submission and review system}

I am pleased to inform authors and reviewers of the new online submission and review system at OEM. Developed by Highwire Press (CA, USA), Bench>Press is a fully integrated electronic system which uses the internet to allow rapid and efficient submission of manuscripts. It also allows the peer review process to be conducted entirely online. The main aim is to speed up the frequently frustrating progress from submission to publication.

Authors can submit their manuscript in any standard word processing software. Standard graphic formats accepted include: .jpg, .tiff, .gif, eps, etc. (Please note: multi page powerpoint files are not accepted by the BM Publishing Group.) The text and graphic files are automatically converted to PDF for ease of distribution and reviewing purposes. Authors are asked to approve their submission before it formally enters the reviewing process. On approval, the submission is passed to the editor and/or reviewers via the web. All transactions are secure.

To access the system click on "SUBMIT YOUR MANUSCRIPT HERE" on the OEM homepage: http://www.occenvmed.com, or you can access the submission site directly at http://submitoem.bmijournals.com.

We are very excited with this new development and would encourage authors and reviewers to use the system where possible. It really is simple to use and should greatly improve on the current peer review process. Full instructions can be found on Bench>Press http://submitoem.bmijournals.com and OEM online at http://www.occenvmed.com. Please contact Natalie Davies, Project Manager, ndavies@bmigroup.com.

Anne Cockcroft

Editor, OEM 